300

GROWTH OF THE FETAL GUINEA PIG: PHYSICAL AND CHEMICAL CHARACTERISTICS. John $W$. Sparks, Jean R. Girard, Soomant Callikan and Frederick C. Battaglia. College de France, paris, and University of Colorado School of Medicine, Department of Pediatrics, Denver

Achievement of the intrauterine growth rate is a goal frequently used in nutrition of preterm infants. Data on the chemical composition of the human are limited and there is curiously little similar data in experimental animals. We studied physical and chemical macronutrient accretion in the fetal guinea pig, a species in which the high fat content and rapid growth rate emphasize the demands of fetal growth upon maternal nutrition. We studied 32 fetuses in 12 litters ranging from 39 days to term $(67 \mathrm{~d})$, analyzing the fetuses for wet weight, dry weight, carbon, nitrogen, fat content, caloric content (bomb calorimeter) and amino acid composition. Body weight increased exponentially with gestational age at $7.1 \% / \mathrm{d}$. Dry weight concentration tripled from $10 \%$ to $30 \%$ by term and total dry weight increased at $10.1 \% / \mathrm{d}$. Fat concentration rose from $2 \%$ at 45 days to $12 \%$ at term and fat content increased $13.5 \% / \mathrm{d}$. The total caloric accretion rate was 100 $\mathrm{kcal} / \mathrm{kg} / \mathrm{d}$ at 45 days, increasing to $220 \mathrm{kcal} / \mathrm{kg} / \mathrm{d}$ at term. Over $60 \%$ of the caloric accretion was due to fat accretion. Caloric values of fat and non-fat dry weight were 9.5 and $4.5 \mathrm{kcal} / \mathrm{g}$ respectively. Amino acids represented $80 \%$ of the total body nitrogen and $46 \%$ of the total body carbon. These data represent the first systematic study of chemical growth during fetal life in any experimental animal, provide accretion measurements unavailable in human studies and demonstrate the importance of fat accretion in caloric demands of fetal growth.

\section{RENAL-HEMODYNAMIC CHANGES IN HYPOXEMIC NORMOCARBIC}

0301 PIGLETS. Jose Strauss, Salha Daniel, Paulo J. Dickstein Oswaldo Trinidade Eduardo Bancalar L. Stanley James and Gaston 2illeruelo. Departments of Pediatrics and Anesthesia, University of Miami, Miami, Florida and Columbia University, New York, New York.

Hypoxemia has been reported to induce a decrease or an increase in renal function depending on various factors. This study assessed some hemodynamic and renal functions in hypoxemic neonatal pigs maintained at a norma1 $\mathrm{PaCO2}$. These results were compared with those of a similar study (Rowe, M.I., Strauss, J.; Pediatr. Res. $7: 411 / 183,1973)$ in which $\mathrm{PaCO} 2$ and $\mathrm{PaO}_{2}$ were decreased. Eleven piglets anesthetized with pentobarbital and mechanically ventilated were studied for a control period of 60 min. at a mean $\mathrm{PaO} 2$ of 76.1 (range 60-96) $\mathrm{mmHg}$ and after $60 \mathrm{~min}$. ventilation with $10-12 \% 02$ to attain a mean Pa02 of 33.4 (range 24-51) $\mathrm{mmHg}$. The following increases were documented after 60 min. of hypoxemia; cardiac output, from 0.72 to $0.85 \mathrm{~L} / \mathrm{min}$; mean arterial blood pressure from 102.5 to $117 \mathrm{mmHg}$; urine volume from 0.027 to $0.063 \mathrm{ml} / \mathrm{min} / \mathrm{kg}$. Arterial blood $\mathrm{pH}$ decreased from 7.450 to 7.392 . A1l changes were significant at $p<0.05$. These urinary results are similar to those obtained in piglets under Ketamine anesthesia, breathing spontaneously $10 \% 02$, and whose $\mathrm{PaCO2}$ decreased markedly but whose cardiovascular variables vere unchanged. It is concluded that hypoxemia induces a diuresis and natriuresis in piglets independent of changes in $\mathrm{PaCO} 2$, cardiac output or mean arterial blood pressure.
CYCLOHEXIMIDE INHIBITS LYSOSOMAL PROTEOLYSIS OF ENDO302 GENOUS BUT NOT EXOGENOUS PROTEINS. Jess G. Thoene and Pediatrics, Ann Arbor.

Cystinotic fibroblasts accumulate lysosomal cystine from the degradation of endogenous and exogenous cystine-containing proteins. Lysosomal cystine accumulation can be modulated by the addition of cystine rich proteins to the culture medium or by labelling the endogenous protein pool with $35(S)$-cystine for varying periods. Cultures of cystinotic fibroblasts were incubated in $35(\mathrm{~S})$ -cystine-containing medium $(40 \mathrm{mCi} / \mathrm{mmol})$ for 4,24 , or $48 \mathrm{hr}$; treated with cysteamine for $30 \mathrm{~min}$. to produce cystine depletion, and replaced in unlabelled medium with or without $100 \mathrm{M}$ cycloheximide ( $\mathrm{CHX}$ ). The plates were harvested after $24 \mathrm{hr}$ in unlabelled medium and the amount of $35(S)$-cystine accumulation determined by high

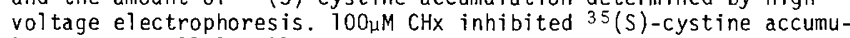
lation from all labelling periods. Results are expressed as CPM/ $10^{6}$ cells of $35(\mathrm{~S})$-cystine $x 10^{4}: 4$ hrs-control $1.46+.50$, CHx 0.34

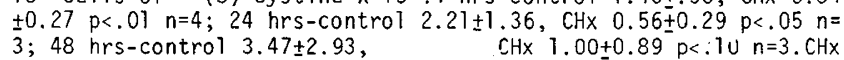
also increased the percent of radioactivity which was acid soluble (cells \& medium) at $24^{\circ}$ after all labelling periods (values in \%) $4 \mathrm{hr}$ control $49.5 \pm 14.6$, CHx $67 \pm 3.2 \mathrm{p}<.05 ; 24 \mathrm{hr}$ control $41 \pm 7.2$, $\mathrm{CHx} 52.6 \pm 5.5 \mathrm{p}<.10: 48 \mathrm{hr}$ control $37 \pm 7.2$, CHx $48.1 \pm 1.7 \mathrm{p}<.05$. CHx had no effect on the accumulation of cystine from BSA added to the cul ture medium:control $0.45 \mathrm{nmol} / 10^{6} \mathrm{cel} 1 \mathrm{~s}$, CHx $0.48 \mathrm{nmol} / 10^{6}$ cells, $\quad \mathrm{P}>0.5 \mathrm{n}=3$. CHx, a known inhibitor of protein synthecells, $\quad P>0.5 n=3$. CHx, a known inhibitor of protein synt
sis, also inhibits the $7 y$ sosomal degradation of endogenous but not exogenous proteins, yet appears to enhance overall proteolysis.
BIOCHEMICAL EVIDENCE OF CARDIOMYOPATHY IN † 303 GUINEA PIGS EXPOSED IN UTERO TO ALCOHOL. John Staley. University of Minnesota Medical School, Hennepin County Medical Center, and Veterans Administration Medical Center, Departments of Pediatrics and Pathology, Minneapolis.

We hypothesized that modest maternal ethanol intake would deleteriously affect developing fetal myocardium. Pregnant guinea pigs were given either water (C), $n=13$, or $2 \frac{1}{2} \%$ ethanol $(E t O H), n=11$, for the last $\frac{1}{2}$ of pregnancy ( $12 \%$ of calories). At birth, progeny body and heart weights were measured, and cardiac sarcoplasmic reticulum (SR) was weights were measured, and cardiac sarcoplasmic reticulum (SR) was
isolated for determination of $\mathrm{Ca}^{++}$uptake, $\mathrm{Ca}^{++}$binding, and $\mathrm{Ca}^{++}$ isolated for determin

Maternal mortality was not significantly different between groups: $0 \%$ in C, $18.2 \%$ in EtOH ( $p>0.10)$. Litter sizes, proportion of progeny born alive, and progeny body weights in $\mathrm{C}$ and $\mathrm{EtOH}$ were similar $(p>0.10)$. Despite similar body weights, heart weight/body weight ratios of EtOH's were less than C's: $4.16 \pm 0.65(n=38)$ vs $4.61+0.66(n=29)$ $\mathrm{gm} / \mathrm{kg}(p<0.005)$. Ca+t flux was also less in EtOH's than C's: Ca ${ }^{++}$ uptake $132 \pm 23$ (4) vs $209 \pm 4$ (5) nM/mg Pr/min (p 0.001); Ca binding 26 \pm 8 (5) vs $53 \pm 2(5) \mathrm{nM} / \mathrm{mg} \operatorname{Pr} / 4 \mathrm{~min}(\mathrm{p}<0.001) ; \mathrm{Ca}^{++}$stimulated ATPase $0.7 \pm 0.3(5)$ vs $1.2 \pm .01$ (5) $\mu \mathrm{M} / \mathrm{mg} \operatorname{Pr} / 10 \mathrm{~min}(p<0.01)$. Modest consumption of ethanol during pregnancy significantly alters
$\mathrm{Ca}^{++}$flux in isolated cardiac SR of the newborn guinea pig. These findings are similar to those observed in adults with alcoholic cardiomyopathy. These data suggest that altered cardiac excitationcontraction may contribute to the production of certain features of the fetal alcohol syndrome.

\section{4} DIRECT PHARMACOLOGIC EFFECTS OF DHT ON THE ALVEOLAR TYPE II CELL IN VITRO. J.S. Torday, Department of Pediatrics (Physiology),
Harvard Medical School, Boston, MA 02115

Previous studies from our laboratory have demonstrated that dihydrotestosterone (DH'T) inhibits the production of pulmonary surfactant in vivo and its de novo synthesis in tissue culture (J. Cell Biology, 97, 86a, 1983). Studies in tissue culture suggest that DHT has no effect on the fibroblast-type II cell interaction which gives rise to surfactant, but blocks this, mechanism in response to cortisol at very low doses $\left(<10^{-8} \mathrm{M}\right)$
comparable to the circulating level of androgens in the fetus and to the $\mathrm{K}_{\mathrm{d}}$ of the androgen receptor. More recent studies suggest that $10^{-7} \mathrm{M}$ to $10^{-5} \mathrm{M}$ DHT stimulates the growth of the fetal type II cell by $40-100 \%$ while reducing the synthesis of saturated phosphatidylcholine in a reciprocal manner. These results may explain the observed in vivo effects of DHT initially results may explain the observed in vivo effects of DHT initially
on the female fetuses $\left(10^{-8} \mathrm{M}\right)$ and at pharmacologic levels on both on the female fetuses $\left(10^{-8} \mathrm{M}\right)$ and at pharmacologic levels on both
sexes at serum androgen levels at an order of magnitude greater. We conclude that the native sex difference in pulmonary surfactant production is due to the effects of androgen on mesenchymal-epithelial interactions, but that DHT may have direct, pharmacologic effects on type II cell maturation as well. (Supported by NIH Grant 非LL28315-02). 